\title{
A SURVEY OF SPATIAL DISORIENTATION INCIDENCE IN POLISH MLLTARY PILOTS
}

\section{RAFAŁ LEWKOWICZ ${ }^{1}$ and MARCIN PIOTR BIERNACKI ${ }^{2}$}

\author{
Military Institute of Aviation Medicine, Warsaw, Poland \\ ${ }^{1}$ Simulator Study and Aeromedical Training Division \\ ${ }^{2}$ Department of Aviation Psychology
}

\begin{abstract}
Objectives: The study aimed to establish the current incidence and severity of spatial disorientation (SD) in Polish military pilots when flying different aircraft types over their entire careers, and to determine how SD training and pilots' flight experience might benefit their recognition of situations that may cause SD. Material and Methods: Overall, 176 military Polish pilots (aged $33.8 \pm 7.72$ years, the number of flying hours: 1194 \pm 941 ) flying different aircraft types, who attended the aviation medicine course, were surveyed and asked to report their episodes of SD. To collect anonymous data, a postal SD questionnaire (INFO PUB 61/117/5) was used. Results: In the overall incidence rate of SD (96\%), the most commonly experienced SD illusion was "loss of horizon due to atmospheric conditions" (81\%). More SD incidents were reported by pilots who had received SD training. Some differences in the categories of the most commonly experienced SD illusion episodes between aircraft types were found. A severe episode adversely affecting flight safety was categorized by $10 \%$ of the respondents. Conclusions: In Polish military aviation, episodes of SD are a significant threat to aviation safety. There is evidence for the beneficial effects of SD training in the improvement of pilots' ability to recognize those factors that lead to SD. Int J Occup Med Environ Health. 2020;33(6):791-810
\end{abstract}

Key words:

aviation medicine, human error, simulation and training, illusions, aviation safety, military aviation

\section{INTRODUCTION}

Spatial disorientation (SD) is a deadly threat to aviation safety which poses a significant risk for both rotary and fixed-wing pilots [1,2]. While flying, SD may appear as a result of the pilot's misperception of the aircraft position, attitude or motion, in relation to the earth or other points of reference (e.g., other aircraft) [3,4]. A degraded visual environment (induced by clouds, darkness, or floating snow or sand), where the pilot does not have a clear view of the horizon, as well as distractions and poor crew resource management, strongly predispose to the incidence of SD.

In fact, $\mathrm{SD}$ is mentioned as the underlying contributing aeromedical factor in fatal aviation mishaps [1,5]. If not quickly recognized and resolved, SD can lead to incor- rect control inputs, resulting in an entry into unusual attitudes, a loss of control in-flight or controlled flight into terrain [6]. While SD mishaps are usually fatal, their share in all accidents ranges $2.5-30.8 \%$ in different aircraft types $[1,2]$. For Polish military aircrew, that share was calculated many years ago at around $8 \%$ [7].

The main approaches that have been used to prevent SD during manually-controlled, human-crewed flights include: pilot selection, a design of orienting displays and SD training [8,9]. Unfortunately, despite enhancements in the selection procedure [10], cockpit instrumentation [11] and training efforts [2], the SD-related accident rate remains consistently high. Of these 3 above-mentioned categories of SD countermeasures, the authors of this paper

Received: March 9, 2020. Accepted: July 1, 2020

Corresponding author: Rafał Lewkowicz, Military Institute of Aviation Medicine, Simulator Study and Aeromedical Training Division, Krasińskiego 54/56, 01-755 Warsaw, Poland (e-mail: qrtx@wp.pl). 
decided to focus on raising the awareness of the SD problem among pilots through education and training. According to Standardisation Agreement (STANAG) No. 3114 (Aeromedical Training of Flight Personnel) [12], each North Atlantic Treaty Organization (NATO) aviator is to gain some knowledge of spatial orientation and disorientation (mechanisms underlying disorientation and management of disorientation in flight), which "should be reinforced by a practical demonstration of the effects of vestibular stimulation using a rotating chair or a suitable disorientation device to provide each student with personal experience of some of the common illusions." Some of the Air Standardisation Coordinating Committee (ASCC) instructions and practical experience in SD (named as the Air Standard) provide a standardized academic definition for SD, define the minimum aviation medicine/physiology training in SD for aircrew (AIR STD 61/117/01), specify details of the required (and agreed) classroom curriculum (ASCC INFO PUB61/117/8), and make general recommendations about ground-based and in-flight demonstration and training (AIR STD 61/117/14). They are incorporated in STANAG 3114 [12].

As in most NATO countries, initial and refresher (at intervals up to 5 years) SD training (theoretical and practical) in the Polish Army is conducted at the Military Institute of Aviation Medicine (Wojskowy Instytut Medycyny Lotniczej - WIML, Warsaw, Poland) and follows the provisions of NATO STANAG 3114 and STANAG 7147 which deal with night vision goggles (NVGs). The classroom-based lecture series includes the physiology of human sensory systems involved in orientation, mechanisms of spatial orientation and disorientation, illusions, human factors and disorientation, SD hazards with NVGs and illustration of recent SDrelated accidents. The issues of SD with $\mathrm{NVG}$ operations are covered in detail during the training of novice NVG aircrew. Ground-based SD demonstrations are conducted using the Gyro IPT trainer (Environmental Tectonics Corp., USA). All pilots and flight personnel who have basic flying skills experience recommended illusions and limitations of their orientation senses, with the non-participating aircrew members as observers [13]. Such SD training is validated by a written examination (based on the lectures); however, no formal process has been established to monitor the effectiveness of the SD demonstration sortie.

In Poland, there is no structured in-flight SD demonstration sortie, but some qualified flying instructors raise certain SD-relevant issues during in-flight training. In-flight training includes the demonstration of unusual attitudes to student pilots, requiring them to recover the aircraft. However, its aim is primarily to teach instrument flight rule skills and unusual attitude recovery rather than an assessment of the factors that allow this unusual attitude to develop.

Next to some form of SD training (ground-based and/or in-flight demonstrations), military aircrew are also educated based on the outcome of an investigation of aircraft incidents and accidents. Matthews et al. [14] noted that published reports of aircraft mishaps might be valuable in raising the awareness of the SD problem; however, these documents provide little information about the frequency with which SD affects pilots' performance. Therefore, the survey questionnaire may be an additional source of information about the SD experience among aircrews.

To evaluate the impact of new aircraft or to display technologies on pilots' susceptibility to SD illusions, as well as to track changes in the incidence of SD over time and across different aircrew populations, Project Group 117 of ASCC Working Party 61 developed a SD survey questionnaire (INFO PU18B 61/117/5) [15,16]. So far, several surveys have been conducted using this standardized tool $[14,17,18]$ and a self-authoring questionnaire $[19,20]$. These surveys have reported some commonalities in the SD experiences of aviators. Even though ground-based SD training has been systematically conducted at WIML since 2008, no studies on the incidence and severity of SD in Polish military pilots, and on how the training affects the actual SD incidence, have been carried out. 


\section{Aim of the study}

The primary purpose of the study was to establish the current incidence and severity of SD in Polish military pilots when flying different aircraft types over their entire careers. Another goal was to determine how ground-based SD training and pilots' flight experience might benefit their recognition of situations that may cause SD. This study also intends to enhance the understanding of the causes of SD in Polish military pilots, so future training and research can be developed to help prevent SD-related accidents. Like in the previously cited surveys [14,17], the authors of this study focused on the frequency and type of the SD experienced. They asked the pilots to report the SD incidences that they had recognized and could categorize accordingly.

The authors' intention was also to ascertain the frequency and severity of the pilots' SD experience relative to their pilot colleagues who had not taken part in any SD demonstration training. In addition, the emphasis was placed on whether the amount of SD training increased the pilots' awareness of the conditions predisposing to SD and improved their ability to recognize the factors that lead to this phenomenon. Finally, to perceive the SD incidence in a wider context, the authors compared and evaluated how the results obtained from this study differed from the results of questionnaire-based SD surveys performed in other countries $[14,17,18]$.

\section{MATERIAL AND METHODS}

\section{Participants}

Questionnaires were completed by 176 Polish military pilots (including 11 females) who participated in the initial or refresher ground-based SD training. This training was a part of the aeromedical training of flight personnel conducted at WIML according to STANAG 3114.

The mean age of the pilots was $33.8 \pm 7.72$ years, ranging 21-55 years. The respondents included active duty fixed-wing pilots $(\mathrm{N}=102)$ and rotary-wing pilots $(\mathrm{N}=74)$.
The aviators were divided into fast-jet (TS-11, MiG-29, Su-22, F-16 and PZL-130), rotary-wing (Mi-2, Mi-8/17, Mi-14, Mi-24, SW-4 and W-3), multi-engine (C-295M and M-28) and trainer (DA-20) aircraft groups. The mean number of total flying hours was $1194 \pm 941$, ranging $80-4390 \mathrm{~h}$.

Participation in the survey was entirely voluntary. Additionally, all questions were asked in a way to protect personal information; therefore, the subjects were kept anonymous, except for their general positions and flight experience levels, which were requested to establish population demographics. The study protocol was approved by the Ethics Committee (WIML, Warsaw, Poland); an informed consent form was completed by each subject prior to participating in the study.

It was assumed that the surveyed pilots were adequate to serve as a sample representation of all active duty pilots from the tri-services of the Polish Armed Forces (PAF) (i.e., Polish Land Forces, the Polish Air Force and the Polish Navy).

\section{Equipment and materials}

Survey content

To collect data regarding pilots' experience with SD, a 2-page double-checked Polish version of the ASCC WP61 questionnaire of SD [16] was used. Next to the questions about the pilots' characteristics and participation in previous SD training, the questionnaire included questions related to the experience of specific factors and in-flight illusions contributing to episodes of SD. To make sure that each specific illusion listed in the questionnaire was understandable to the pilots, a brief description was given. To collect data about the pilots' most recent episode of SD, pick-lists were used. In the last question, the respondents were asked to rate the worst ever episode of SD in their current aircraft type. The SD questionnaire was described in detail in an earlier SD survey by Holmes et al. [17]. 


\section{Procedure}

An anonymous questionnaire was distributed to the pilots during their participation in the aviation medicine course in September 2013-June 2014. The questionnaires were completed and collected after an hour of theoretical lectures (classroom instruction) on spatial orientation and disorientation, but before the simulator-based SD demonstration and training. It was assumed that all the surveyed pilots honestly answered all of the questions in the questionnaire. The respondents who answered $<50 \%$ of all questions were excluded from the analysis. The returned survey data were entered into Excel version 2016 (Microsoft, USA).

\section{Statistical analysis}

In order to compare the results with data obtained from other surveys conducted on the Royal Air Force (RAF) [17], the United States Air Force (USAF) [14] and the Royal Netherlands Air Force (RNLAF) [18] aviators (using the same or a near-identical questionnaire), the aircraft types were categorized as fast-jet, multi-engine, trainer and rotary-wing. Using the same classification of variables, the authors investigated the effects of the following independent variables: age, training rating, aircraft type, total flying hours and hours-on-type. The pilots were also divided into 1 of the following 2 groups: those who had received SD training and those who had not. Due to the fact that in-flight SD training is not part of the standard training program of Polish pilots, in this analysis, SD training refers only to ground-based SD demonstration and training. Like in previous studies [14,17,18], the dependent variables included the frequency of illusions or other situations that may cause SD, and the severity rating of the most recent and worst ever SD experience (Holmes et al. [17]). The illusions classified to the display category were analyzed together (roll-reversal error, instrument malfunction and forward-looking infrared systems), with the exception of helmet mounted displays (HMDs) or head-up displays (HUDs), and NVG-related illusions which were analyzed separately. The miscellaneous illusion category was split into the following 3 groups: central psychological ("giant hand"/"feeling of detachment"), SD due to distraction or task saturation, and SD due to poor crew coordination. The responses regarding the frequency of episodes of SD were weighted as follows: 0 - "never," 1 - "1-2 incidents," $2-$ " $<5 \%$ of incidents," $3-$ "5-25\% of incidents," and $4-$ - "> $25 \%$ of incidents."

Statistical analysis was carried out by taking into account the type of the dependent variables (dichotomous, categorical, ordinal or continuous). Pearson's correlation test and Spearman's rank correlation test were used to examine dependent variables by age, total flying hours, hours-on-type, training rating and the amount of SD training. The Mann-Whitney U test and Cramer's V correlation test were applied to examine the effects of SD training on SD illusion episodes. Finally, to analyze all dependent variables by aircraft type, a 1-way analysis of variance (ANOVA) with a significance criterion of $p<$ 0.05 was used. If the data did not satisfy an assumption of normality, a non-parametric ANOVA (i.e., the Kruskal-Wallis test) was used. In cases of significance, posthoc tests (by Scheffe and Bonferroni) were performed to identify the source of any significant effects within each factor.

Additionally, to clarify whether it was possible to predict the incidence of episodes of SD in certain aircraft types using the following variables: total flying hours, hours-ontype and participation in ground-based SD training, a multivariate regression analysis was carried out. This analysis was used for each aircraft type. The data were analyzed with IBM SPSS version 17.0 (IBM Corporation, USA).

\section{RESULTS}

A total of 176 pilots completed the questionnaires, and the number of valid forms was 158 . The most common types of aircraft flown were W-3 (rotary-wing) and TS-11 (fast-jet). The pilot's flight experience and the classifica- 
Table 1. Pilots' flight experience by aircraft type, based on the survey conducted among Polish military pilots in the Military Institute of Aviation Medicine (Warsaw, Poland) in September 2013-June 2014

\begin{tabular}{|c|c|c|c|c|c|}
\hline \multirow{3}{*}{ Aircraft type } & \multirow{3}{*}{$\begin{array}{l}\text { Pilots' age } \\
\text { [years] } \\
(\mathrm{M} \pm \mathrm{SD})\end{array}$} & \multicolumn{4}{|c|}{$\begin{array}{c}\text { Flying time } \\
{[\mathrm{h}]}\end{array}$} \\
\hline & & \multicolumn{2}{|c|}{ total } & \multicolumn{2}{|c|}{ on a given type } \\
\hline & & $\mathrm{M} \pm \mathrm{SD}$ & $\min .-\max$ & $\mathrm{M} \pm \mathrm{SD}$ & $\min .-\max$ \\
\hline Fast-jet $(\mathrm{N}=58)$ & $34.4 \pm 8.31$ & $1246 \pm 958$ & $191-4390$ & $864 \pm 867$ & $34-4390$ \\
\hline Multi-engine $(\mathrm{N}=20)$ & $38.8 \pm 6.99$ & $1789 \pm 1032$ & $250-3800$ & $1002 \pm 611$ & $200-2600$ \\
\hline Trainer $(\mathrm{N}=12)$ & $22.5 \pm 1.73$ & $123 \pm 59$ & $80-300$ & $104 \pm 64$ & $60-300$ \\
\hline Rotary-wing $(\mathrm{N}=68)$ & $33.9 \pm 6.02$ & $1164 \pm 823$ & $160-3100$ & $844 \pm 657$ & $40-2800$ \\
\hline
\end{tabular}

Fast-jet: TS-11 ( $=27)$, MiG-29 ( $\mathrm{N}=9$ ), F-16 ( $\mathrm{N}=12)$, Su-22 ( $\mathrm{N}=3)$, PZL-130 ( $=7$ ).

Multi-engine: C-295M (N = 5), M-28 ( $\mathrm{N}=15)$.

Rotary-wing: Mi-24 ( $\mathrm{N}=5)$, Mi-14 ( $\mathrm{N}=3), \operatorname{Mi}-8 / 17(\mathrm{~N}=7), \operatorname{Mi}-2(\mathrm{~N}=12), \mathrm{SW}-4(\mathrm{~N}=11), \mathrm{W}-3(\mathrm{~N}=30)$.

Trainer: DA-20 $(\mathrm{N}=12)$.

tion of aircraft used in this study are shown in Table 1. The mean $(\mathrm{M})$ total and current flight experience of the pilots by aircraft type is also presented.

Of all the pilots surveyed, only $37.3 \%$ were previously provided with SD training (33.9\% in combination with in-flight SD demonstrations) and $13.9 \%$ with in-flight SD demonstrations only (the latter were included into the group of pilots who did not receive SD training). The average elapsed time since the last SD training was 40.9 months ( $\mathrm{SD}=17.2$ months), ranging 12-72 months. The training was conducted at WIML primarily by aeromedical physiologists $(89.2 \%)$ in the form of classroom didactic lectures with some ground-based demonstration of classical illusions. The shares of previous experience in SD training by lecture, ground demonstration and in-flight demonstration were $83.1 \%, 81.4 \%$ and $33.9 \%$, respectively.

\section{Rating of SD training}

The pilots generally highlighted the equivalent beneficial effects of both the in-flight illusion demonstrations and the ground training they had received, with $93.2 \%$ of the pilots rating their training as satisfactory or better. The respondents' ratings of SD training are presented in Figure 1.

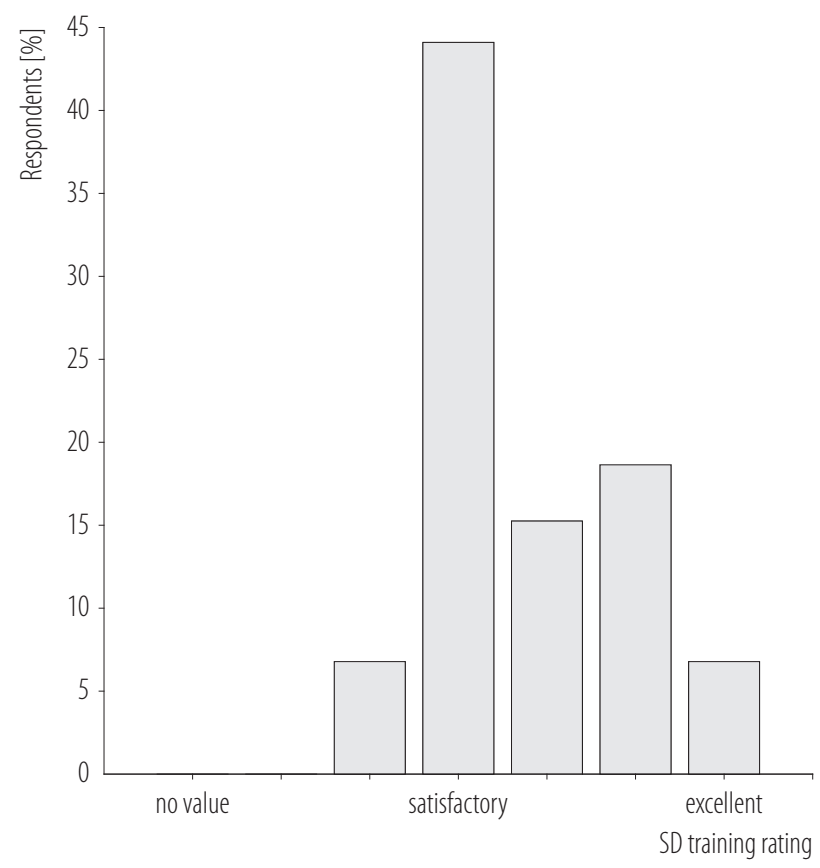

Less than satisfactory $-6.8 \%$, satisfactory or better $-93.2 \%$.

Figure 1. Pilots' ratings of spatial disorientation (SD) training, based on the survey conducted among Polish military pilots in the Military Institute of Aviation Medicine (Warsaw, Poland) in September 2013-June 2014

\section{Incidence rate of in-flight illusions}

The general incidence rate of in-flight illusions in the surveyed pilots was $96 \%$. Six young pilots claimed that they 
had never experienced any kind of illusion. Among the remaining respondents, $10(6.3 \%)$ reported that they had experienced 1-2 illusions, 83 (52.5\%) had experienced $3-10$ different types of illusions, and $57(36.1 \%)>10$ different types of illusions.

The most common flight illusion episode was the "loss of the horizon due to atmospheric conditions" (81\% of the surveyed pilots), followed by episodes of SD resulting from the "sloping horizon" (55\%). The most commonly experienced episodes of SD (in the rank order) for all pilots are provided in Table 2. In order to compare how the results obtained in this study differed from the results of questionnaire-based SD surveys on aviators from other countries (i.e., RAF [17], USAF [14], RNLAF [18] and HAF [21]), the authors also included these data in Table 2.

Among the 4 analyzed aircraft groups (fast-jet, multi-engine, trainer and rotary-wing), the most common illusion was "loss of horizon due to atmospheric conditions" $(86 \%$, $75 \%, 83 \%$ and $77 \%$, respectively). Other types of illusions varied depending on the aircraft category. The most frequently experienced (top 40\%) flight illusion episodes for the pilots by aircraft type are illustrated in Table 3 . The results of SD surveys from RAF [17] USAF [14] and RNLAF [18] are also presented.

\section{Recent and worst ever episodes of SD}

When asked to report their most critical episodes of SD, $69 \%$ of the pilots reported at least $\geq 1$ minor episode (flight safety was not at risk), $21 \%$ reported $\geq 1$ significant episode (flight safety could have been at risk under different conditions), and 10\% $\geq 1$ severe episode (flight safety was at risk), over their entire careers. Rating the severity of their most recent episode of SD (within 6 months prior to the survey), 114 pilots responded and classified their incidents, with $81 \%$ as minor, $12 \%$ as significant, and $7 \%$ as severe, with regard to flight safety. These results are illustrated in Figure 2.

\section{Correlations of SD incidence}

The main variables (categories of SD illusions) and their correlations are shown in Table 4. The SD illusions experienced by the pilots were mainly influenced by their age, total flying hours and hours-on-type.

Although the absolute values of all correlations presented in Table 4 are $<0.5$ (predominantly small to medium associations), some significant correlations are presented below. The analysis revealed positive effects of age, total flying hours $(\mathrm{p}<0.01)$ and hours-on-type $(\mathrm{p}<0.01)$ on all illusions ( $p<0.01)$, visual illusions $(\mathrm{p}<0.01)$ and displays illusions $(\mathrm{p}<0.05)$ experienced by the respondents. The covariates of the same factors (age, total flying hours and hours-on-type) were also found to have some negative effects on episodes of SD during NVG use $(p<0.05$, $\mathrm{p}<0.01$ and $\mathrm{p}<0.01$, respectively).

The experience of body sense illusions was affected by training rating (a negative linear relation) and SD training. The pilots who had received ground-based SD training reported more body sense illusions than those who had not participated in such training $(p<0.05)$. However, the pilots who rated SD training higher had fewer body sense illusions than those who did not highlight the beneficial effects of such training ( $p<0.05)$.

Considering that experienced pilots (aged $>35$ years) may report conflicts more often than those who are younger (aged $\leq 35$ years) [22], an additional analysis of betweensubjects effects (depending on received SD training) was carried out. This analysis revealed that older pilots who participated in SD training were more likely to report body sense illusions than those who had not yet received such training. However, this difference was found to be significant at a moderate level $(\mathrm{t}(63)=-1.794, \mathrm{p}=0.078)$. In the case of less experienced pilots (aged $\leq 35$ years), the same analysis revealed significant differences in terms of all illusions $(\mathrm{t}(91)=-1.940, \mathrm{p}=0.05)$ and body sense illusions $(\mathrm{t}(91)=-2.181, \mathrm{p}=0.032)$ between those who received and did not receive $\mathrm{SD}$ training. 
Table 2. Rank order and share of the experienced illusions, based on the survey conducted among Polish military pilots in the Military Institute of Aviation Medicine (Warsaw, Poland) in September 2013-June 2014

\begin{tabular}{|c|c|c|c|c|c|c|}
\hline \multirow[t]{2}{*}{ Rank of the experienced illusion } & \multirow[t]{2}{*}{ Category } & \multicolumn{5}{|c|}{$\begin{array}{l}\text { Respondents } \\
{[\%]}\end{array}$} \\
\hline & & PAF & RAF & USAF & RNLAF & HAF \\
\hline 1. Loss of horizon due to atmospheric conditions & $\mathrm{V}$ & 81 & 82 & 69 & 70 & 38 \\
\hline 2. Sloping horizon & $\mathrm{V}$ & 55 & 75 & 66 & 76 & 24 \\
\hline 3. Giant hand & $\mathrm{O}$ & 55 & 31 & 38 & 17 & n.a. \\
\hline $\begin{array}{l}\text { 4. Misleading altitude cues from ground texture } \\
\text { (e.g., over flat water, small trees) }\end{array}$ & $\mathrm{V}$ & 50 & 79 & 50 & 66 & n.a. \\
\hline $\begin{array}{l}\text { 5. Loss of horizon caused by blowing sand, dust or snow } \\
\text { (brown-out/white-out) }\end{array}$ & $\mathrm{V}$ & 45 & 56 & 33 & 45 & n.a. \\
\hline 6. Autokinesis & $\mathrm{V}$ & 43 & 43 & 37 & 45 & n.a. \\
\hline 6. Graveyard spiral & BS & 43 & 43 & 32 & 48 & n.a. \\
\hline 7. Tumbling sensation (Coriolis) & BS & 41 & 66 & 61 & 57 & 39 \\
\hline 7. Leans & BS & 41 & 92 & 76 & 67 & 42 \\
\hline 8. Feeling of detachment (high altitude) & $\mathrm{O}$ & 37 & 17 & 11 & 12 & n.a. \\
\hline 8. Roll-reversal error & $\mathrm{D}$ & 37 & 31 & 23 & 24 & 24 \\
\hline 9. Night approach & $\mathrm{V}$ & 36 & 60 & 58 & 58 & n.a. \\
\hline 9. False sense of yaw & $\mathrm{V}$ & 36 & 20 & 31 & 36 & n.a. \\
\hline 9. Graveyard spin & BS & 36 & 7 & 6 & 8 & n.a. \\
\hline 10. Distraction/task saturation & $\mathrm{O}$ & 35 & 66 & 61 & 45 & n.a. \\
\hline 11. Elevator illusion & BS & 34 & 35 & 37 & 39 & n.a. \\
\hline 11. False sense of inversion & BS & 34 & 18 & 23 & 27 & n.a. \\
\hline 12. Misjudgment of position in night formation & $\mathrm{V}$ & 29 & 37 & 38 & 38 & n.a. \\
\hline 12. Poor crew co-ordination & $\mathrm{O}$ & 29 & 50 & 40 & 21 & n.a. \\
\hline $\begin{array}{l}\text { 13. Inability to read instruments clearly following recovery } \\
\text { from maneuver }\end{array}$ & $\mathrm{V}$ & 26 & 29 & 22 & 12 & n.a. \\
\hline 14. Instrument malfunction & $\mathrm{D}$ & 23 & 24 & 13 & 16 & n.a. \\
\hline 15. Inappropriate use of sun, lights as vertical cue & $\mathrm{V}$ & 22 & 17 & 24 & 28 & n.a. \\
\hline 16. Undetected drift (rotary-wing only) & BS & 18 & 55 & 6 & 38 & n.a. \\
\hline 17. Head-down displays (problem interpreting information) & V & 16 & 30 & 20 & 26 & n.a. \\
\hline 18. G-excess & BS & 15 & 33 & 36 & 37 & n.a. \\
\hline 19. Caused by NVG use & $\mathrm{V}$ & 14 & 48 & 12 & 50 & n.a. \\
\hline 19. False sense of pitching up & BS & 14 & 34 & 44 & 30 & n.a. \\
\hline 20. Vertigo caused by flickering light & $\mathrm{V}$ & 13 & 8 & 20 & 30 & n.a. \\
\hline 21. SD while using drifting/descending flare as a reference & $\mathrm{V}$ & 9 & 10 & 9 & 21 & n.a. \\
\hline 21. False sense of pitching down & BS & 9 & 28 & 36 & 29 & n.a. \\
\hline
\end{tabular}


Table 2. Rank order and share of the experienced illusions, based on the survey conducted among Polish military pilots in the Military Institute of Aviation Medicine (Warsaw, Poland) in September 2013-June 2014 - cont.

\begin{tabular}{lcccccc}
\hline \multirow{2}{*}{ Rank of the experienced illusion } & & \multicolumn{5}{c}{ Respondents } \\
& Category & \multicolumn{5}{c}{ [\%] } \\
\cline { 3 - 7 } & & PAF & RAF & USAF & RNLAF & HAF \\
\hline 21. Caused by HUD use & D & 9 & 13 & 10 & 15 & n.a. \\
22. Caused by FLIR use & D & 4 & 11 & 9 & 27 & n.a. \\
23. Caused by HMD use & D & 3 & 2 & 2 & 28 & n.a. \\
\hline
\end{tabular}

n.a. - not available.

BS - body sense illusion; D - displays illusion; O - other; V - visual illusion.

HAF - Hellenic Air Force; PAF - Polish Armed Forces (the current study); RAF - Royal Air Force; RNLAF - Royal Netherlands Air Force; USAF - United States Air Force.

FLIR - forward-looking infrared system; HMD - helmet mounted display; HUD - head-up display; NVG - night vision goggles.

Table 3. Share of the most frequently experienced illusions (top 40\%) by aircraft type, based on the survey conducted among Polish military pilots in the Military Institute of Aviation Medicine (Warsaw, Poland) in September 2013-June 2014

\begin{tabular}{|c|c|c|c|c|}
\hline \multirow[t]{2}{*}{ Aircraft type and experienced illusions } & \multicolumn{4}{|c|}{$\begin{array}{c}\text { Respondents } \\
{[\%]}\end{array}$} \\
\hline & PAF & RAF & USAF & RNLAF \\
\hline \multicolumn{5}{|l|}{ Fast-jet } \\
\hline loss of horizon due to atmospheric conditions & 86 & 86 & 78 & 82 \\
\hline sloping horizon & 76 & 75 & 72 & 86 \\
\hline giant hand & 71 & $<50$ & 41 & $<70$ \\
\hline graveyard spiral & 53 & $<50$ & 31 & $<70$ \\
\hline distraction/task saturation & 53 & 65 & 65 & 72 \\
\hline tumbling sensation (Coriolis) & 52 & 71 & 62 & 79 \\
\hline misjudgment of position in night formation & 48 & $<50$ & 75 & 81 \\
\hline feeling of detachment (high altitude) & 48 & $<50$ & 7 & $<70$ \\
\hline false sense of yaw & 47 & $<50$ & 39 & $<70$ \\
\hline misleading altitude cues & 45 & 84 & 65 & 76 \\
\hline autokinesis & 45 & $<50$ & 41 & $<70$ \\
\hline graveyard spin & 45 & $<50$ & 4 & $<70$ \\
\hline leans & 45 & 92 & 84 & 88 \\
\hline roll-reversal error & 43 & $<50$ & 20 & $<70$ \\
\hline elevator illusion & 41 & $<50$ & 37 & $<70$ \\
\hline \multicolumn{5}{|l|}{ Multi-engine } \\
\hline loss of horizon due to atmospheric conditions & 75 & n.a. & 72 & 72 \\
\hline sloping horizon & 70 & n.a. & 78 & 74 \\
\hline misleading altitude cues & 60 & n.a. & 59 & 55 \\
\hline autokinesis & 55 & n.a. & 52 & 45 \\
\hline
\end{tabular}


Table 3. Share of the most frequently experienced illusions (top 40\%) by aircraft type, based on the survey conducted among Polish military pilots in the Military Institute of Aviation Medicine (Warsaw, Poland) in September 2013-June 2014 - cont.

\begin{tabular}{|c|c|c|c|c|}
\hline \multirow[t]{2}{*}{ Aircraft type and experienced illusions } & \multicolumn{4}{|c|}{$\begin{array}{c}\text { Respondents } \\
{[\%]}\end{array}$} \\
\hline & PAF & RAF & USAF & RNLAF \\
\hline \multicolumn{5}{|l|}{ Multi-engine - cont. } \\
\hline graveyard spiral & 50 & n.a. & 32 & $<40$ \\
\hline night approach & 45 & n.a. & 83 & 68 \\
\hline false sense of yaw & 45 & n.a. & 42 & 47 \\
\hline giant hand & 45 & n.a. & 38 & $<40$ \\
\hline false sense of inversion & 40 & n.a. & 20 & $<40$ \\
\hline feeling of detachment (high altitude) & 40 & n.a. & 14 & $<40$ \\
\hline \multicolumn{5}{|l|}{ Trainer } \\
\hline loss of horizon due to atmospheric conditions & 83 & 72 & 65 & 72 \\
\hline elevator illusion & 67 & $<50$ & 37 & 56 \\
\hline graveyard spiral & 67 & $<50$ & 31 & $<50$ \\
\hline leans & 58 & 86 & 74 & 94 \\
\hline graveyard spin & 50 & $<50$ & 9 & $<50$ \\
\hline feeling of detachment (high altitude) & 50 & $<50$ & 11 & $<50$ \\
\hline giant hand & 42 & $<50$ & 37 & $<50$ \\
\hline \multicolumn{5}{|l|}{ Rotary-wing } \\
\hline loss of horizon due to atmospheric conditions & 77 & 81 & 66 & 84 \\
\hline loss of horizon due to sand/snow & 65 & 63 & 76 & 90 \\
\hline poor crew co-ordination & 65 & 55 & 68 & n.a. \\
\hline misleading altitude cues & 55 & 80 & 80 & 84 \\
\hline giant hand & 45 & $<50$ & 55 & n.a. \\
\hline
\end{tabular}

Abreviations as in Table 2.

The statistical analysis of the episodes of SD caused by poor crew coordination revealed a positive correlation between this factor and hours-on-type $(\mathrm{p}<0.05)$. The maximum amount of SD training received by the pilots amounted to 4 courses, with $51.2 \%$ of the respondents having had no SD training or in-flight illusion demonstrations at all. The share of the pilots receiving 1 , 2, 3 or 4 courses of SD training amounted to $56 \%, 35 \%$, $5 \%$ and $4 \%$, respectively. No statistically significant relationship was found between the amount of SD train- ing received by the pilots and the number of SD illusions experienced.

Moreover, ANOVA revealed that there was an effect of aircraft type on all the illusion categories under analysis, except for displays illusions and SD illusions caused by HUD/HMD use (Figure 3). Fast-jet pilots reported more incidents of SD resulting from overall and body sense illusions than trainer aircraft pilots $(p<0.05$ and $p<0.01$, respectively). They also reported more central psychological SD illusions than rotary-wing pilots $(\mathrm{p}<0.001)$. A dif- 
Table 4. Correlations of dependent variables - illusion categories and independent variables, based on the survey conducted among Polish military pilots in the Military Institute of Aviation Medicine (Warsaw, Poland) in September 2013-June 2014

\begin{tabular}{|c|c|c|c|c|c|c|}
\hline Illusion category & Age & Training rating & SD training & $\begin{array}{l}\text { Total flying } \\
\text { hours }\end{array}$ & Hours-on-type & $\begin{array}{c}\text { Amount } \\
\text { of SD training }\end{array}$ \\
\hline All illusions & $\mathrm{r}=0.234^{* *}$ & $\varrho=-0.079$ & $\mathrm{U}=2718$ & $\mathrm{r}=0.255^{* *}$ & $\mathrm{r}=0.231^{* *}$ & $\varrho=0.077$ \\
\hline Visual illusions & $\mathrm{r}=0.335^{* *}$ & $\varrho=-0.024$ & $\mathrm{U}=2878$ & $\mathrm{r}=0.354^{* *}$ & $\mathrm{r}=0.293^{* *}$ & $\varrho=0.144$ \\
\hline Body sense illusions & $\mathrm{r}=0.078$ & $\varrho=-0.016^{*}$ & $\mathrm{U}=2395^{*}$ & $\mathrm{r}=0.100$ & $r=0.123$ & $\varrho=0.024$ \\
\hline Displays illusions & $r=0.168^{*}$ & $\varrho=-0.098$ & $\mathrm{U}=2581$ & $\mathrm{r}=0.178^{*}$ & $\mathrm{r}=0.171^{*}$ & $\varrho=-0.042$ \\
\hline $\begin{array}{l}\text { Central psychological illusions } \\
\text { (giant hand and detachment) }\end{array}$ & $\varrho=0.039$ & $\varrho=-0.043$ & $\mathrm{U}=2823$ & $\varrho=0.045$ & $\varrho=0.022$ & $\varrho=0.047$ \\
\hline $\begin{array}{l}\text { SD caused by distraction } \\
\text { or task saturation }\end{array}$ & $\varrho=0.052$ & $\varrho=-0.037$ & $\mathrm{U}=2807$ & $\varrho=0.052$ & $\varrho=0.042$ & $\varrho=0.202$ \\
\hline SD due to poor crew co-ordination & $\varrho=0.112$ & $\varrho=-0.109$ & $\mathrm{U}=2666$ & $\varrho=0.130$ & $\varrho=0.172^{*}$ & $\varrho=0.122$ \\
\hline HUD/HMD & $\varrho=0.077$ & $\varrho=0.039$ & $\mathrm{U}=2862$ & $\varrho=0.093$ & $\varrho=0.012$ & $\varrho=0.126$ \\
\hline NVG & $\varrho=-0.174^{*}$ & $\varrho=0.043$ & $\mathrm{U}=2879$ & $\varrho=-0.247^{* *}$ & $\varrho=-0.329^{* *}$ & $\varrho=-0.014$ \\
\hline Most recent SD & $\varrho=-0.107$ & $\varrho=0.014$ & $\mathrm{~V}=0.010$ & $\varrho=-0.100$ & $\varrho=-0.075$ & $\varrho=-0.059$ \\
\hline Worst ever SD & $\varrho=0.012$ & $\varrho=0.001$ & $\mathrm{~V}=0.081$ & $\varrho=0.016$ & $\varrho=0.006$ & $\varrho=0.055$ \\
\hline
\end{tabular}

*p $<0.05 ; * * \mathrm{p}<0.01$.

r - Pearson's correlation; @ - Spearman' rank correlation; U - Mann-Whitney U test; V - Cramer's V correlation.

Other abbreviations as in Table 1.

ferent relation was found for SD due to poor crew coordination, where rotary-wing pilots reported more incidents of SD resulting from this factor than aviators flying fast-jet $(p<0.001)$, multi-engine $(p<0.001)$ and trainer aircraft $(p<0.001)$. It was also found that rotary-wing pilots most often experienced SD episodes during NVG use compared to fast-jet $(\mathrm{p}<0.001)$, multi-engine $(\mathrm{p}<0.05)$ and trainer aircraft $(\mathrm{p}<0.05)$ pilots (Figure 3$)$.

A multivariate regression analysis showed that, on some platforms, the total flying hours and participation in a ground-based SD training could be used as predictors of the incidence of SD illusions. For fast-jet pilots, the regression model proved to be statistically significant $(\mathrm{F}(3,57)=4.069, \mathrm{p}=0.011)$ and among the analyzed factors, total flying hours $(\beta=0.598, p=0.024)$ and SD training $(\beta=0.245, p=0.05)$ turned out to be significant predictors of the incidence of SD illusions. The regression model was also statistically significant in the case of rotary-wing pilots $(\mathrm{F}(3,67)=3.822, \mathrm{p}=0.014)$; however, only total flying hours proved to be a significant predictor $(\beta=0.547, p=0.049)$.

\section{DISCUSSION}

This SD questionnaire-based study is the first survey of Polish military pilots. The authors used it to investigate the incidence and severity of episodes of SD over their entire careers and during their flying different aircraft types. The goal was also to determine how the groundbased SD training affected the actual SD incidence, and to ascertain the frequency and severity of the pilots' SD experience relative to their colleagues who had not taken part in SD training. Finally, the authors were interested in whether the amount of SD training received by the pilots affected the number of SD illusions reported by them.

In the civil aviation environment, prevalence data for SD and its countermeasures (especially SD training) are less commonly available; therefore, to compare the results of this research, the authors chose data from military avia- 
tion studies. It is worth noting that, in all previously cited SD surveys [14,17,18,20,23,24], and also in the present study, the pilots reported the incidences of SD that they had recognized and could categorize accordingly.

\section{Incidence rate of in-flight illusion}

Many studies [6,25] indicate that, during their entire careers, pilots can experience an SD incidence in the range of $90-100 \%$. This is also confirmed by the results of this study, in which $96 \%$ of the surveyed pilots reported that they had experienced $\geq 1$ in-flight SD illusion. These findings indicate that the more flying hours a pilot accumulates, the more likely he/she has been disorientated at least once.

In this study, "loss of horizon due to atmospheric conditions" was the most commonly experienced SD illusion, followed by SD caused by "sloping horizon," the "giant hand" illusion and "misleading attitude cues" (Table 2). Besides the "giant hand" illusion, these results are in agreement with the most recent SD incidence surveyed among RNLAF military pilots [18]. However, according to the majority of earlier surveys $[20,21,23,24]$, the most frequently reported SD phenomenon was the "leans" illusion. Therefore, it is surprising that this illusion (Table 2) was rarely reported by the pilots involved in this study (41\%, rank 7). In the previous studies [14,17], conducted using the same SD questionnaire, the "leans" illusion was also indicated as the most common phenomenon.

It is worth mentioning that the "leans" illusions occur to pilots who have been maneuvering the aircraft in instrument meteorological conditions. This is reported to occur after a sudden return (with a supra-threshold roll rate) to wings-level flight following a prolonged turn or a gradually increased bank angle that was not noticed by the pilot. It gives the pilot a sense that the aircraft is flying with 1 wing low despite the attitude indicator, and other confirmatory instruments showing straight and level flight. To recover the perception of a wings-level attitude,

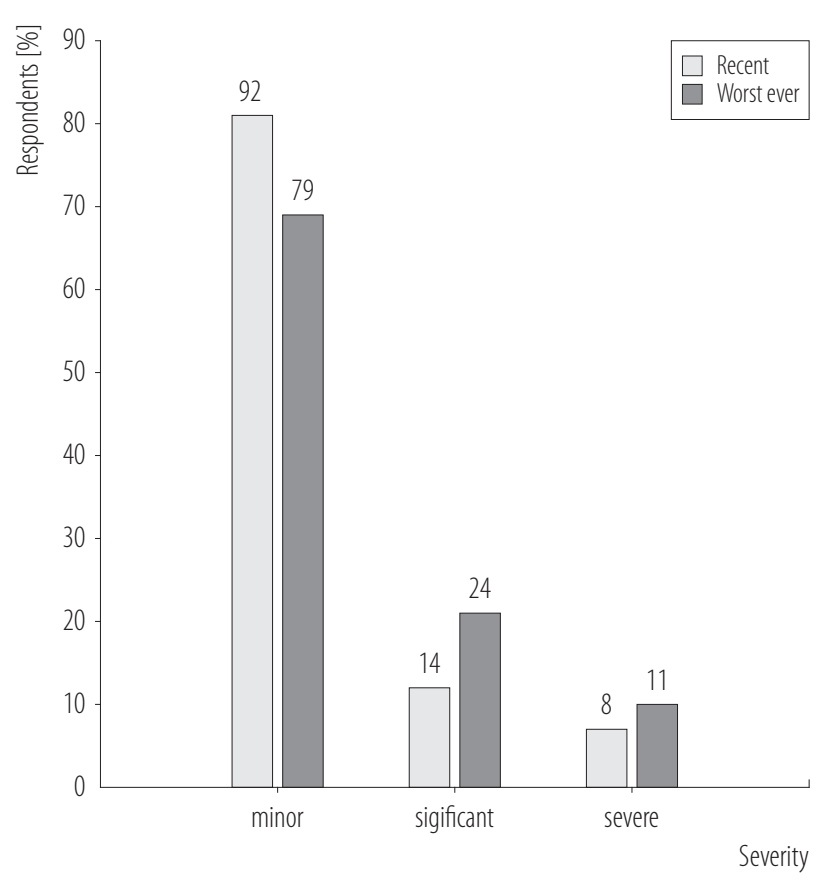

The value above the bars indicates the number of respondents in each category.

Figure 2. Distribution of respondents' classification of their most recent and worst ever episodes of spatial disorientation (SD), based on the survey conducted among Polish military pilots in the Military Institute of Aviation Medicine (Warsaw, Poland) in September 2013-June 2014

the pilot will make an effort to re-enter the previous banking turn of the aircraft (wrongly felt to be straightand-level) when he/she actually is in a coordinated turn. If the pilot does not recognize his/her misperception and continues to bank the aircraft, it may result in a high-angle-of-bank and an unusual attitude. This illusion may last for minutes and, despite the bank and rotation of the aircraft, it may give the pilot the impression of the level flight, which is a typical feeling of the "graveyard spin" illusion. The leans disappear as soon as there is an unambiguous view of the ground.

The graveyard spin is an illusion that can occur when the pilot intentionally or unintentionally enters a spin, and he/she becomes less aware of the sense of this rotation as it continues. If the pilot performs a spin correction, he/she may perceive spinning in the opposite direction, which 


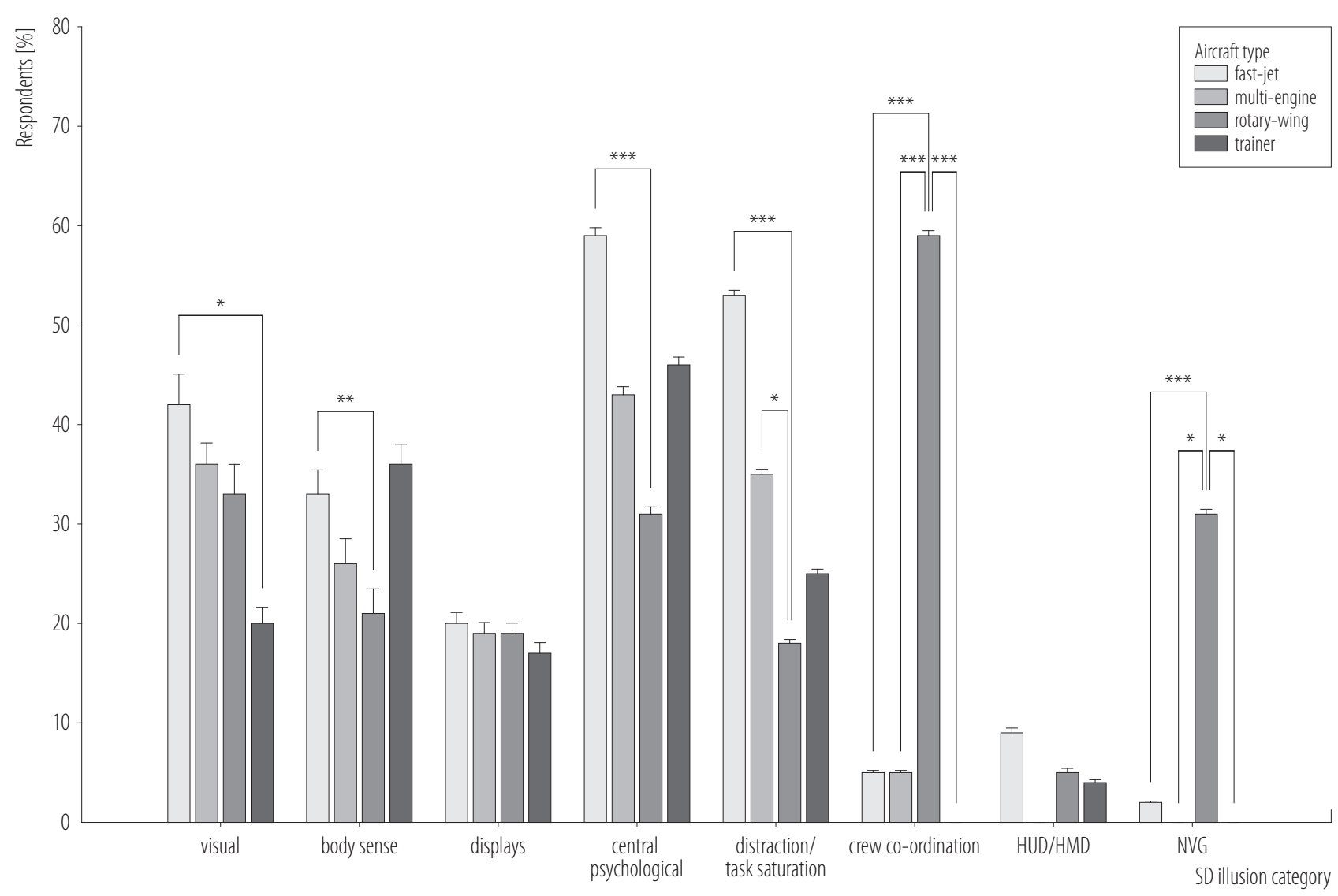

SD - spatial disorientation.

${ }^{*} \mathrm{p}<0.05 ;{ }^{* *} \mathrm{p}<0.01 ;{ }^{* * *} \mathrm{p}<0.001$.

The error bars represent standard deviation.

Figure 3. Effects of the aircraft type on the illusion category, based on the survey conducted among Polish military pilots in the Military Institute of Aviation Medicine (Warsaw, Poland) in September 2013-June 2014

may give similar sensations to those occurring during the "leans" illusion. It is worth mentioning here that the pilot experiencing disorientation about the roll axis (e.g., the "leans" illusion) may also feel a force like a giant hand, trying to push 1 wing down and hold it there [26]. Therefore, it may be correct to state that the perceptual sensation is similar between the "leans" and "giant hand" illusions, and may be similar to the sensation experienced by the pilot who performs a spin correction when suffering from the "graveyard spin" illusion.

As a result, these 3 in-flight illusions (i.e., "leans," "graveyard spin" and "giant hand") can often be confused by pilots (es- pecially inexperienced aviators) and incorrectly recognized. This may explain why a low incidence of the "leans" illusion ( $41 \%$ vs. $92 \%$ in RAF, $76 \%$ in USAF and $67 \%$ in RNLAF) and a relatively high rate of reported "graveyard spin" $(36 \%$ vs. $7 \%$ in RAF, $6 \%$ in USAF and $8 \%$ in RNLAF) and "giant hand" (55\% vs. $31 \%$ in RAF, $38 \%$ in USAF and $17 \%$ in RNLAF) illusions were reported in this survey. An alternative explanation for this particular difference (a low incidence of the "leans" illusion) may be that episodes of the "leans" are generally minor [24]. With a slight sensation, pilots may not have perceived this illusion and the sensation appeared only when another illusion occurred. 
Like previous findings [14,17,18,21], the "tumbling sensation (Coriolis)" was the second, preceded only by the "leans" illusion, the most common body sense illusion reported in this study; however, RAF, USAF and RNLAF aviators experienced this illusion more often $(66 \%, 61 \%$ and $57 \%$, respectively). This difference may result from a lack of the pilots' efficient knowledge about this phenomenon. Among the respondents, only $56 \%$ participated in SD training.

The "roll-reversal error" was another factor often reported by Polish pilots (37\%) contributing to episodes of SD. It was slightly less frequently reported by other aviators (Table 2). One of the factors that might have contributed to the increased "roll-reversal error" in this study was the confusion of the pilots on interpreting the attitude indicator (artificial horizon display) [27]; older pilots were initially trained with an eastern model of the attitude indicator (moving aircraft attitude reference, which is used in the fast-jet MiG-29 and the rotary-wing Mi-2, Mi-8/17, Mi-14 and Mi-24), and then they were transferred to aircraft with a western model of the attitude indicator (moving horizon attitude reference, which is used in the fast-jet F-16 and the rotary-wing SW-4 and W-3). It is worth noting that these were primarily fast-jet pilots (Table 3 ) who could not readily transfer their flight experience.

Poor crew coordination was reported as a contributing factor in $29 \%$ of SD episodes, having been encountered in the previous surveys in 50\% of RAF [17], $40 \%$ of USAF [14] and 21\% of RNLAF [18] respondents. Much to the authors' surprise, there was a positive correlation between hours-on-type and SD experiences due to poor crew coordination. It reflects the fact that, with an increasing number of flying hours, pilots will experience more such episodes. A possible explanation is that experienced pilots are more able to recognize this type of an SD episode [14]. On the other hand, it would be expected that experienced pilots should demonstrate high crew coordination skills. However, this finding indicates that extensive flight experience may not translate into improved crew coordination management. If there is a high incidence of SD due to poor crew coordination, the importance of training the flight crew is emphasized to avoid their loss of situational awareness due to task load [17].

In this study, the episodes of SD induced by "distraction due to task saturation" were reported by $35 \%$ of the pilots, which is nearly half of that found by other researchers $[14,17,23]$. This difference may be explained by the low complexity of tasks performed during flying, or by the fact that this SD experience may not be so recognizable or memorable. It is also worth considering that this result corresponds to a relatively small contribution of poor crew coordination to SD episodes, which involved $29 \%$ of the surveyed pilots. It may additionally explain why aviators from other studies, who had experienced more crew coordination-related episodes of SD, had often reported distractions due to task saturation. The high incidence of the SD episodes resulting from distractions due to task saturation and/or poor crew coordination indicates a need to develop and include in ground-based SD training a specific disorientation scenario (multi-task and highworkload flight simulations), such as cockpit distraction while flying in a degraded visual environment [2]. Interestingly, SD illusion episodes during NVG-aided flights or problems interpreting information resulting from the use of HMDs or HUDs were experienced by relatively low numbers of the surveyed pilots $(14 \%, 3 \%$ and $9 \%$, respectively). These figures are not dissimilar to a survey conducted by Sipes and Lessard [23] among experienced instructor pilots, or by Matthews et al. [14] among USAF aviators. However, there is a difference of experiencing NVG-related episodes compared to those illusions reported by RAF [17] and RNLAF [18] respondents (Table 2). This difference may be explained by the relatively low use of NVGs among the pilots involved in the present study. This is probably due to the rotary-wing pilots who are more likely to use NVGs than fast-jet or transport aircraft aviators. 
Similarly, an interpretation of information displayed on HUDs or HMDs is the aircraft-related problem that was reported mainly by fast-jet pilots. This problem may also be caused by the pilots who convert to a new type of HUD or HMD on a different aircraft [14]. It can be confirmed by the most recent findings [11], where the layout and design of instrument display in the cockpit of the aircraft, as well as in HMD, were responsible for SD in $54.5 \%$ of fast-jet pilots.

It is not entirely clear why the shares for the illusions of a false sense of pitching up (14\%) and pitching down (9\%) are almost 3 times lower compared to the results of previous studies [14,17,18] (Table 2). The explanation for this particular difference may be that the surveyed pilots could be more aware of somatogravic illusions, or it could be a result of the type of flying they had experienced.

An overview of the remaining results of this study revealed that the SD illusions arising from "loss of horizon due to sand/snow," "false sense of inversion," "misjudgment of position in night flying," "instrument malfunction," "inability to read it clearly following recovery from maneuver," or "inappropriate use of sunlight as a vertical cue" (Table 2) were reported to range $22-43 \%$ of the time and were not dissimilar to previous studies $[14,17,18]$.

Despite some differences in the frequency of SD incidents reported by Polish pilots in relation to the frequency reported by their colleagues from other countries (RAF, USAF, RNLAF and HAF), it is worth noting that, after nearly 2 decades since the first surveys were conducted [14,17], using improved and more advanced groundbased SD training, most SD episodes are reported at a similar percentage and still pose a serious threat for military aviation. One of the possible reasons for the lack of decline in this percentage can be indicated by new designs of aircraft with unusual dynamic and visual environments for pilots, and an increase in the frequency of NVG flights. This has been noticed by Holmes et al. [17] and still seems to apply to pilots flying aircraft currently in service.

\section{Predictors of SD incidence}

An analysis of the relationship between pilot's age, total flying hours or hours-on-type with their experiences of SD illusions has shown that the latter 2 factors can serve as predictors of these incidents. A further analysis revealed that total flying hours proved to be a significant predictor on both fast-jet and rotary-wing platforms. These findings demonstrate that the more flight experience a pilot had (in terms of total flying hours and hours-on-type), the more episodes of all illusions, including visual illusions and displays illusions, they reported. It simply reflects the greater chance of experiencing episodes of SD illusions with an increasing number of hours flown. It was also noticed by Matthews et al. [14] that the pilots' experience was a good predictor of SD incidents; more experienced pilots just have more opportunities to experience SD illusions.

Special attention should be paid to pilots having been exposed to NVG-related illusions. In this case, the analyzed factors appeared to have an opposite effect on the frequency of SD illusions (Table 4). The younger and less experienced pilots proved to be more prone to an illusion during the use of NVGs. This finding mainly applies to rotary-wing pilots (Figure 3), and although NVGs enhance their ability to operate in low illumination conditions, NVG-aided vision is limited relative to natural human daylight vision. As a result, it may contribute to perceptual errors and lead to sensory illusions.

\section{SD experience depending on the aircraft type}

With regard to the types of illusions depending on the aircraft category, the authors found some similarities as well as differences in the top $40 \%$ of the most frequently experienced SD episodes (Table 3). Two ("loss of horizon due to atmospheric conditions" and "graveyard spiral" which, as explained earlier, probably applies to the "leans" illusion) of the top 5 most reported SD illusions were the same among fast-jet, multi-engine and trainer aircraft pilots. Although the order of the most frequently reported 
illusions in this study differed from the order found in other illusion-based surveys $[14,17,18]$, their certain correspondence can be demonstrated.

For fast-jet pilots, among their top $3 \mathrm{SD}$ experiences (Table 3), i.e., "loss of horizon due to atmospheric conditions," "sloping horizon" and the "leans" illusion (as was explained earlier, the surveyed pilots may have incorrectly recognized this illusion as the "graveyard spiral" and/or "giant hand" illusion), 2 were the same as reported by USAF [14] and RAF [17] (the "leans" and "loss of horizon" illusions) or RNLAF [18] (the "leans" and "sloping horizon" illusions) respondents. In the case of multi-engine aircraft pilots, there was also some similarity between the results of this study (the "sloping horizon" and "loss of horizon" illusions) and the results found in the abovementioned studies.

Among the 3 highest ranked SD experiences in rotarywing pilots, the authors found "loss of horizon caused by atmospheric conditions" blending the earth and the sky and loss of horizon caused by blowing sand, dust or snow (brown-out/white-out)," which was consistent with previous findings $[14,17,18]$. However, it was not clear why, in these results (the top 3), there were no reports of "undetected drift" and "misleading altitude cues from ground texture (e.g., over flat water, small trees)," while these illusions were frequently reported by pilots from other countries (Table 3). A possible explanation for this difference may be that the surveyed pilots were unable to recognize these illusions, or they did not have many opportunities to experience them.

In this study, among the top $3 \mathrm{SD}$ experiences reported by trainer aircraft pilots were "loss of horizon due to atmospheric conditions" and "leans/graveyard spiral." These findings were not dissimilar to the surveys conducted by Matthews et al. [14], Holmes et al. [17], and Pennings et al. [18]. To sum up, it is worth noting that, for all types of aircraft, 2 of the top 3 most frequently reported SD experiences were the same among these surveys. Neverthe- less, some dissimilarities can be explained by differences in the capabilities of aircraft. For example, "loss of horizon due to sand/snow," "undetected drift" and "vertigo caused by flickering light" are unique for rotary-wing platforms, whereas "G-excess" and "false sense of pitching up" are typical of fixed-wing platforms.

Investigating the correlation between the types of SD illusions and specific types of aircraft, the authors of this study found that fast-jet pilots reported more SD events than other aircraft aviators, especially rotary-wing aviators (Figure 3). Matthews et al. [14] noted that this could be due to the design of the SD questionnaire, where most of the SD illusions specific to the fast-jet aircraft environment were included.

The only exceptions were the episodes of SD caused by poor crew coordination and NVG use (Figure 3), where rotary-wing pilots reported significantly more incidents of SD resulting from these factors than pilots flying other aircraft types. A possible explanation for the first factor is that rotary-wing pilots spend much of their time in a close distance to the ground or obstacles, where their coordination is a critical issue in flight safety. The more frequent reporting of episodes of SD triggered by the use of NVGs may be explained by the fact that rotary-wing pilots are more likely to use NVGs than other aviators, as has already been explained in this section. The above-mentioned differences in the SD experience between different aircraft types confirm that illusions specific to airframe are essential to incorporate into SD training [2].

\section{Recent and worst ever episodes of SD}

The severity of the most recent episode of SD was classified mainly as minor; however, there were also some ratings of significant and severe episodes. Compared to other studies [17-19], significant episodes were reported less frequently, while severe episodes were reported more frequently. 
In the case of the worst ever episode of SD rated by the surveyed pilots as significant or severe in relation to flight safety (Figure 2), Matthews et al. [14] found that they involved nearly three-quarters of unrecognized SD episodes. In this study, they were rated as severe (when flight safety was at risk) by $10 \%$ of the pilots, which is comparable to the $8 \%$ or $11 \%$ found by Pennings et al. [18], and by Boril et al. [19], respectively. However, another illusion-based survey [17] concluded that $18 \%$ of respondents rated these episodes as severe. The authors explained that such a high percentage outcome in their research may have occurred because the surveyed pilots may have rated the severity of their most recent and worst ever episodes of SD as opposed to their impact on flight safety. To clarify this issue, a revision of this question (the last question in the survey) was proposed by Holmes et al. [17]. Moreover, considering that the severity of the episode of SD was significantly higher for night flying as compared to day flying [28], this question could be additionally phrased in such a way that the time of the day would be taken into account when reporting an episode of SD.

Discussing the worst ever episodes of SD, it is also worth mentioning that younger pilots (aged $\leq 35$ years) were more likely to have rated their worst ever episode as severe than older pilots (aged $>35$ years) [24]. In this study, it was also found that the younger pilots $(\mathrm{M}=$ $22.5 \pm 1.73$ years) flying trainer aircraft more often rated their most recent and worst ever episodes of SD as severe (flight safety was at risk).

\section{Participation in SD training}

Based on similar surveys [14,17], the authors expected that pilots who had received SD training were more able to recognize and categorize their episodes of SD. Therefore, they should have reported more episodes of SD than those who had not participated in any SD training. The obtained results did partially confirm this expectation; the pilots who received SD training most commonly reported body sense illusions. This was in line with the authors' subsequent findings that the pilots who rated SD training higher reported more body sense illusions than those who rated it as less satisfactory (Table 4).

Unfortunately, although $>90 \%$ of the pilots rated the training in spatial orientation satisfactory or above, it was not possible to ascertain why only just body sense illusions were more frequently reported. Perhaps, this category of illusions might be more recognizable or memorable. An alternative explanation as to why these pilots did not report more types of SD episodes may be that they mainly experienced simulator-induced SD illusions. Certainly, such illusions differ from those demonstrated during an actual flight. Unfortunately, probably due to a greater threat and high costs, in-flight SD demonstrations are often cut back.

An interesting finding is that SD training significantly increased the ability of the less experienced pilots (aged $\leq 35$ years) to recognize in-flight illusions, whereas in older pilots, it had little effect. It means that SD training is particularly important for younger pilots who do not have flight experience or sufficient knowledge of the potential flight hazards. As was previously noted by Holmes et al. [17], a more frequently reported SD incidence provides evidence for the beneficial effects of SD training on the recognition of SD events, which is especially true for novice pilots.

Much to the authors' surprise, there was no difference in the rating of the most critical and recent SD episodes between the pilots who had not received SD training and those who completed it. Based on previous findings [17], it was expected that, since the pilots who received SD training reported a greater incidence of $\mathrm{SD}$, they would also rate their most critical and recent episodes with greater severity. A possible explanation for this difference was that the surveyed pilots rated the severity of their most recent and worst ever episodes of SD regardless of how these episodes affected flight safety. This may be caused 
by an incorrect form of the question in the questionnaire, as was earlier noticed by Holmes et al. [17].

The results of the statistical analysis showed the lack of any relationship between the amount of SD training received by pilots and the number of SD illusions reported by them (Table 4). Likewise, in a recent study [18], the researchers found that the amount of SD training received by RNLAF pilots was not significantly correlated with the number of their SD experiences. It may suggest that the amount of training is not an issue affecting the incidence of SD illusions.

\section{Limitations of the study}

In addition to the above-mentioned achievements, some limitations of the present study should be considered. Firstly, in using the WP61 postal SD questionnaire, it was difficult to distinguish those situations in which the pilots experienced an illusion or had become disorientated due to the illusion [17]. It was considered by the authors of this questionnaire [17] that, to give a close picture of the disorientating aspects of flying, the questions included should be phrased in such a way that differentiates between these situations.

Secondly, comparing the prevalence and incidence rates among aviators can be problematic depending on how the definition of an SD illusion is applied. Despite the authors' efforts to correctly translate the survey into Polish, they are aware that some definitions may have been misunderstood by the pilots. It should be noted, however, that the researcher could explain the illusion listed in the survey at the participant's request.

Thirdly, since in most cases the SD event is not recognized by the pilots [3], their responses may not reflect the actual incidence rates of illusions or SD episodes. An in-flight illusion can only be recognized if flight instruments or other visual cues (e.g., natural horizon) are used to create awareness of the actual situation. Then, it might be assumed that the pilot is no longer disorientated [17]. However, although some pilots may have experienced SD illusions, they could report that they have never been confused due to illusion because, relying on flight instruments, they always successfully resolve the perceptual conflict and are aware of the aircraft's actual spatial orientation [4].

Finally, the number of incidents reported by the pilots could also be affected by the presence of the researcher/ SD instructor. Although the study was anonymous, such a situation could have caused the pilots, fearing possible consequences (though wrongly) due to their high susceptibility to illusions, to give incomplete answers. As a result, the SD illusions could have been underreported.

\section{CONCLUSIONS}

Gathering information from the pilots on the frequency, severity and types of SD illusions experienced in their entire flying career, the authors have attempted to expand their knowledge about this phenomenon in Polish aviation. Despite the above-mentioned limitations, this study also intended to enhance the understanding of the causes of SD, and to aid in developing future training and targets for future research to help prevent SD-related accidents. This survey showed that, in Polish military aviation, inflight illusions are also a significant threat to aviation safety. The "loss of horizon due to atmospheric conditions" blending the earth and the sky (e.g., when night flying or when flying in the clouds or in degraded visual conditions) turned out to be the most commonly experienced SD illusion. Compared to previous studies, the authors found lower shares of reported instances of the SD caused by poor crew coordination, distraction due to task saturation or errors in the interpretation of displays (HUD/ HMD). They also identified several factors that might increase the relative risk of SD-related accidents. The first 2 of them (total flying hours and hours-on-type) indicate that the more flight experience a pilot has, the greater chance he/she has to experience episodes of body sense illusion. The next predictor concerns NVG-aided flying 
and reflects that the younger and less experienced pilots are more prone to illusions during NVG use. Considering these factors is a possible way to prevent SD-related mishaps in the future.

The revealed differences in the types of SD illusions experienced by pilots of different aircraft types confirm that the recommendations for SD demonstrations specific to the aircraft type, included in the report by Bless [2], should still be respected. These findings also suggest that it may be beneficial to provide, in this demonstration, specific flight scenarios and environmental conditions on episodes of SD resulting from poor crew coordination and $\mathrm{NVG}$ use by rotary-wing pilots.

This study also sought to determine whether groundbased SD training increased the pilots' general situational awareness, and its effects on SD incidence. The authors provided some evidence (the role of flight experience and receiving SD training) for the potentially beneficial effects of flight illusion demonstrations and training in the improvement of the pilots' ability to recognize those factors that lead to SD. Some pilots were provided with in-flight training to cope with SD (e.g., procedures upon inadvertent entry to instrument meteorological conditions and recovery from unusual attitudes); however, due to its non-standardized form and those pilots constituting a small group of respondents, it was difficult to assess how this training could be beneficial in recognizing situations that may cause SD. The circumstances that provide information about potential mishaps could be valuable in the design of the SD demonstration sortie and severe episodes of SD (reported by $10 \%$ of the surveyed pilots).

The authors agree with Benson and Scott [4] that, although this illusion-based approach to SD does not indicate that a given illusion may definitely lead to an SD-related accident, it is a useful method for providing the quantitative information on the incidence of SD, how illusions confused pilots, and which types of SD illusions pose the biggest safety risk. The authors hope that the results of their study may encourage pilots to report their SD experiences more willingly, knowing that it actually happens to all pilots. Due to the fact that there have been very few SD-related mishaps involving PAF aircraft over the last few decades (maybe there were more such instances, but the reports of the aviation accident investigation board did not mention SD as a causative factor), it is difficult to summarize and compare these findings with the results of such accident investigations. Finally, the authors have made an effort to compare their findings with the results of previous studies, but the fact that SD training affects the incidence of reported episodes of $\mathrm{SD}$, and may differ from those carried out in other countries, makes it difficult to generalize these results to other aviators.

Based on the above-mentioned conclusions, the authors would like to present a few recommendations. Firstly, they uphold the recommendation by Cheung [29] that particular attention should be paid to the lack of standardized in-flight SD training. Specific in-flight scenarios would be valuable for pilots to obtain direct experience in preventing and overcoming SD in a realistic environment.

Secondly, in addition to basic illusion demonstrations (e.g., on the Barany chair or a simple SD simulator, such as the Gyro IPT trainer), ground-based SD training should also contain an element of more advanced instruction and training specific to the aircraft type (e.g., an advanced SD simulator). The PAF should examine the benefits of incorporating SD training into advanced flight simulators (e.g., human training centrifuge). The outcomes of this study may be used in developing future SD demonstrations and training on those simulators.

Finally, it is surprising that, since SD is such a common phenomenon and still poses a considerable threat in aviation, only a few similar studies have been conducted so far. Therefore, the authors encourage SD experts and researchers from other countries to carry out similar investigations using standardized questionnaire-based SD surveys. International cooperation and exchange of in- 
formation on the recognition of circumstances that could lead to in-flight SD and training patterns to cope with this phenomenon may contribute to a significant reduction in this problem prevailing in aviation. Such cooperation will also generate newer ideas for research on SD and its related aspects.

\section{ACKNOWLEDGMENTS}

The authors wish to thank all the pilots for their participation in the study. The authors also wish to extend thanks to the anonymous reviewers for their valuable comments and suggestions for improving the quality of this paper.

\section{REFERENCES}

1. Gibb R, Ercoline B, Scharff L. Spatial disorientation: decades of pilot fatalities. Aviat Space Environ Med. 2011;82(7):717-24.

2. Bles W, editor. Spatial disorientation training - demonstration and avoidance. RTO-TR-HFM-118 AC/323 TP/206. Soesterberg: The Research and Technology Organisation of NATO; 2008. p. 132.

3. Previc FH, Ercoline WR. Spatial disorientation in aviation. Progress in Astronautics and Aeronautics Vol. 203. 1st ed. Zarchan P, editor. Reston, VA: American Institute of Aeronautics and Astronautics, Inc.; 2004. p. 600.

4. Benson AJ, Scott JRR. Spatial disorientation in flight. In: Rainford DJ, Gradwell DP, editors. Ernsting's Aviation Medicine. 4th ed. Cornwall: Edward Arnold Ltd; 2006. p. 433-58.

5. Newman RL, Rupert AH. The magnitude of the spatial disorientation problem in transport airplanes. Aerosp Med Hum Perform. 2020;91(2):65-70, https://doi.org/10.3357/AMHP. 5442.2020 .

6. Patterson FR, Cacioppo AJ, Gallimore JJ, Hinman GE, Nalepka JP. Aviation spatial orientation in relationship to head position and attitude interpretation. Aviat Space Environ Med. 1997;68(6):463-71.

7. Szczepanski C, Skibniewski W, Gasik M, Truszczyński O. Standard flight simulator as a spatial disorientation training device. In: Modeling and Simulation Technologies Conference.
Denver, CO: American Institute of Aeronautics and Astronautics; 2000.

8. Cheung B. Comprehensive approach to pilot disorientation countermeasures. In: Vidulich MA, Tsang PS, editors. Advances in Aviation Psychology - Improving Aviation Performance through Applying Engineering Psychology. 3rd ed. New York, NY: Taylor \& Francis Group; 2019. p. 3-23.

9. Lawson BD, Curry IP, Muth ER, Hayes AM, Milam S, Brill JC. Training as a countermeasure for spatial disorientation mishaps: Have opportunities for improvement been missed? In: Mitigating Hazards to Rotary Wing Flight in Degraded Visual Environments STO-EN-HFM-265. The NATO Science and Technology Organization; 2017. p. 3A-1-20, https://doi.org/10.14339/STO-EN-HFM-265.

10. Lewkowicz R, Bałaj B, Francuz P. Susceptibility to flight simulator-induced spatial disorientation in pilots and nonpilots. Int J Aerosp Psychol. 2020;30(1-2):25-37, https://doi. org/10.1080/24721840.2019.1696680.

11. Wang J, Li SC, Lin PC. A psychophysical and questionnaire investigation on the spatial disorientation triggered by cockpit layout and design. Int J Ind Ergon. 2019;72:347-53, https://doi.org/10.1016/j.ergon.2019.06.008.

12. Standardization Agreement Normalization. STANAG 3114 Aeromedical Training of Flight Personnel, Edition 9. Brussels: North Atlantic Treaty Organization; 2018.

13. Cheung B. Recommendations to enhance spatial disorientation training for the Canadian Forces. Report No.: DCIEM, 98-R-32. Toronto: Defence and Civil Institute of Environmental Medicine; 1998.

14. Matthews RSJ, Previc FH, Bunting A. USAF spatial disorientation survey. In: RTO HFM Symposium on Spatial Disorientation in Military Vehicles Causes Consequences and Cures. La Coruña: The Research and Technology Organisation of NATO; 2002. p. 7-1-13.

15. Braithwaite MG. Spatial disorientation: Towards international standardization. In: RTO HFM Symposium on Spatial Disorientation in Military Vehicles: Causes, Consequences and Cures. 2002. p. 34-1-7. 
16. Working Party 61, SD survey postal questionnaire. ASCC INFO PUB 61/117/5. Arlington, VA: Air Standardization Coordinating Committee; 2000.

17. Holmes SR, Bunting A, Brown DL, Hiatt KL, Braithwaite MG, Harrigan MJ. Survey of spatial disorientation in military pilots and navigators. Aviat Space Environ Med. 2003;74(9):957-65.

18. Pennings HJM, Oprins EAPB, Wittenberg H, Houben MMJ, Groen EL. Spatial disorientation survey among military pilots. Aerosp Med Hum Perform. 2020;91(1):4-10, https:// doi.org/10.3357/AMHP.5446.2020.

19. Boril J, Smrz V, Leuchter J, Petru A, Frantis P, Blasch E, et al. Survey of spatial disorientation and sensory illusion among air force pilots. In: 2018 IEEE/AIAA 37th Digital Avionics Systems Conference (DASC). London: IEEE; 2018. p. 1-7, https://doi.org/10.1109/DASC.2018.8569266.

20. Navathe PD, Singh B. Prevalence of spatial disorientation in Indian Air Force aircrew. Aviat Space Environ Med. 1994;65(12):1082-5.

21. Chimonas E, Diamantopoulos I, Markou I, Stathogiannis E. A spatial disorientation survey of Hellenic Air Force pilots. RTO-MP-086. In: RTO HFM Symposium on Spatial Disorientation in Military Vehicles: Causes, Consequences and Cures. La Coruna, Spain, 15-17 April; 2002.

22. Previc FH, Ercoline WR, Evans RH, Dillon N, Lopez N, Daluz CM, et al. Simulator-induced spatial disorientation: effects of age, sleep deprivation, and type of conflict. Aviat Space Environ Med. 2007;78(5):470-7.
23. Sipes WE, Lessard CS. A spatial disorientation survey of experienced instructor pilots. IEEE Eng Med Biol Mag. 2000;19(2):35-42.

24. Durnford SJ. Disorientation and flight safety: A survey of UK Army aircrew. In: Proceedings of the Advisory Group for Aerospace Research and Development Aircraft accidents: trends in aerospace medical investigation techniques AGARD-CP-532. Neuilly-Sur-Seine: AGARD; 1992, p. 32-1-14.

25. Johnson PA, Estrada A, Braithwaite MG, Manning JC. Assessment of simulated spatial disorientation in training U.S. Army aviators. In: RTO HFM Symposium on "Current Aeromedical Issues in Rotary Wing Operations." San Diego: The Research and Technology Organisation of NATO; 1998. p. 15-1-18.

26. Gillingham KK, Wolfe JW. Spatial orientation in flight. Report USAFSAM-TR-85-31. Brooks Air Force Base, IX; 1986.

27. Landman A, Davies S, Groen EL, van Paassen MM, Lawson NJ, Bronkhorst AW, et al. In-flight spatial disorientation induces roll reversal errors when using the attitude indicator. Appl Ergon. 2019;81:102905, https://doi.org/10.1016/ j.apergo.2019.102905.

28. Takada Y, Hisada T, Kuwada N, Sakai M, Akamatsu T. Survey of severe spatial disorientation episodes in Japan Air Self-Defense Force fighter pilots showing increased severity in night flight. Mil Med. 2009;174(6):626-30.

29. Cheung B. Spatial disorientation: More than just illusion. Aviat Space Environ Med. 2013;84(11):1211-4, https://doi. org/10.3357/ASEM.3657.2013.

This work is available in Open Access model and licensed under a Creative Commons Attribution-NonCommercial 3.0 Poland License - http://creativecommons.org/ licenses/by-nc/3.0/pl/deed.en. 